\title{
The Art of Living with Technology: Turning Over Philosophy of Technology's Empirical Turn
}

\author{
Yoni Van Den Eede ${ }^{1} \cdot$ Gert Goeminne $^{2} \cdot$ Marc Van den Bossche $^{3}$
}

Published online: 16 December 2015

(C) Springer Science+Business Media Dordrecht 2015

\begin{abstract}
In this article we seek to lay bare a couple of potential conceptual and methodological issues that, we believe, are implicitly present in contemporary philosophy of technology (PhilTech). At stake are (1) the sustained pertinence of and need for coping strategies as to 'how to live with technology (in everyday life)' notwithstanding PhilTech's advancement in its non-essentialist analysis of 'technology' as such; (2) the issue of whether 'living with technology' is a technological affair or not (or both); and (3) the tightly related question concerning the status of the methodological bedrock of contemporary PhilTech, the 'empirical turn.' These matters are approached from the perspective of the philosophical notion of the 'art of living,' and our argumentation is developed both as a context for and on the basis of the contributions to the special issue 'The Art of Living with Technology.'
\end{abstract}

Keywords Philosophy of technology · Art of living · Empirical turn · Technology use · Reflexivity

Yoni Van Den Eede

yvdeede@vub.ac.be

Gert Goeminne

gert.goeminne@ugent.be

Marc Van den Bossche

mavdboss@vub.ac.be

1 Centre for Ethics and Humanism (ETHU), Culture, Emancipation, Media and Society (CEMESO), Vrije Universiteit Brussel, Pleinlaan 2, 1050, Brussels, Belgium

2 Centre for Sustainable Development, Ghent University, Poel 16, 9000, Ghent, Belgium

3 Centre for Ethics and Humanism (ETHU), Department of Philosophy and Moral Sciences, Vrije Universiteit Brussel, Pleinlaan 2, 1050, Brussels, Belgium 


\section{Introduction}

Technologies nowadays merge with humans to the extent that it is all but impossible to distinguish between who 'we' are and what 'they' are. We define ourselves, even give meaning to life, by way of technology. This process of meaning-making can be framed as a project, a work that one must carry out on a daily, personal-existential basis. But the process comes in different sizes and shapes. Not all of it is done in an equally conscious way. Also, the larger frameworks - or worldviews - within which meaning is sought after, can differ: functionalist, consumerist, ethical, ... Depending on where the emphasis lies, another form of 'living with technology' gets instantiated. Interestingly, it appears that the very degree to which one understands oneself as either intertwined with or independent from her technologies/media, may influence implicit or explicit decision-making processes concerning the place and meaning of technologies in one's life. By of way of a preview of this special issue's central gist: the very question — whether living with technology is something technologicalsurfaces as a divisive element in thinking about our, yes, technological lives.

How much guidance is there available in this regard? How to live with technology? In everyday life, the question has an intriguing double-sidedness to it. On one hand, it acquires an acute pertinence in a technology-saturated world. People feel the need for 'digital detoxing,' to offset the purported nefarious effects of information overload brought on by information and communication technologies (ICTs). Parents and children quarrel about the presence of smartphones at the dinner table. We wonder in how far our natural abilities for spatial orientation are affected by the use of a GPS... and so on. On the other hand, however, the question 'how to live with...' is seldom asked in an exhaustive, systematic manner-like for example debates about abortion or nuclear energy elicit the organization of ethics panels or legislative action. True, for instance, parliamentary representatives and citizen initiatives work for more airtight privacy regulations on the Internet. But generally most people's attitude toward privacy on social networks varies from indifference ('I've got nothing to hide') to pragmatism ('It's a trade-off: a bit of my data in exchange for the services offered'). Perhaps these issues, unlike the examples of abortion and nuclear energy, do not (yet) appear to us as matters of life and death, warranting a form of elaborate reflection. No doubt, the lack of specific focus has also something to do with the relative invisibility of some technologies, such as digital media: their capacity to neatly blend in with everyday life-making it hard to assess their impact in and on, exactly, everyday life. But perhaps it is only a matter of time before their pervasive effects on human life show themselves?

In this special issue, we set forth to explore these issues, in general through the prism of 'philosophy of technology,' and in particular by way of the guiding notion, significant in the history of philosophy, of 'the art of living.'

\section{Philosophy of Technology}

The subdomain of philosophy called the philosophy of technology (henceforth PhilTech) has become a fairly institutionalized discipline in recent decades, with its own journals, conferences, and networks. That institutionalization ran parallel with the so-called 'empirical turn'(Achterhuis 2001), instigated and accomplished by some of the pioneers of contemporary PhilTech, such as Don Ihde and Andrew Feenberg. The turn was a reaction against what can now be denominated 'classic' philosophy of technology. This had been 
delivering, for instance in the work of Martin Heidegger and Jacques Ellul, all-encompassing definitions of technology, according to which the latter touches nearly every aspect of life.

In itself, that kind of approach had constituted, around the middle of the twentieth century, a reaction against the then already common-sense disposition of treating technology as something neutral, simply a means to an end. In contrast with such instrumentalist perspective, Heidegger, claiming that "the essence of technology is by no means anything technological" $(1977,4)$, termed technology 'Enframing,' a way of thinking and being that reduces all things to a resource for production and consumption. Ellul equated technology with efficiency, an overarching organizing principle that relentlessly penetrates, reshapes, dominates, and in the end suffocates as good as all domains of human life. Subsequently, in a dramatic and fruitless maneuver, both tried to distance themselves from the massive force that they thought technology to represent; through the expectation of some 'saving power,' or the guidance and comfort of religion.

Over and against classic PhilTech's rather monolithical technology analyses, it is argued, the innovators of contemporary PhilTech placed a systematic look at how people in practical contexts deal with technologies - in the plural. They, too, reached beyond the instrumentalist standpoint, finding, in their own way, the 'essence' of technology to be nothing technological. Only, they weren't searching for essences. True enough, they found technology to be an influential perception-shaping part of the lifeworld, or a strong politically and economically anchored societal cornerstone, but certainly not an all-determining principle, immune to change. We can do more than wait, they discovered: we can co-shape, co-construct, co-design, discuss, denounce, rebuild, adapt, modify, ...

In classic PhilTech, technology was seen to threaten human essence. As a consequence, on a practical level—'in life'-not many other escape routes were being left available, but to fight a losing battle. Post- 'empirical turn' approaches, conversely, chose to base their investigations on a completely different, namely, non-essentialist premise: technology and human nature are not separate entities, they are fundamentally intertwined. This makes the practical-existential counterpart a lot more cheerful: the work of dealing with technology is no longer a vain undertaking, the painful throes and spasms of a death struggle. We are to a certain extent technology, the reasoning goes, so why would or should we fight it? Better get used to the idea of 'being' technological instead and see from there how to "make things better." 1

\section{The Art of Living and Technology}

The material in this special issue grapples with, comes forth from, and finds its place within contemporary PhilTech. On a more practical plane, it has its roots in a colloquium that was organized at the research center iMinds-SMIT of the Free University of Brussels (Vrije Universiteit Brussel) in April 2014. The meeting focused first and foremost on ICT - a focus that still shimmers through in this issue, though we start here from a more general outlook, centering on technology as such. With the colloquium, we endeavored to approach some of the issues at play in the philosophy of technology from a fresh angle. More concretely, we tried to provoke the contributors and participants into 'experimental mode' by inviting them to contemplate issues that busied them, but now from the perspective of

\footnotetext{
${ }^{1}$ As goes the title of a reply (2009) by Peter-Paul Verbeek to reviews of his book What Things Do (2005). 'Let's make things better' used to be, until 2004, the motto of Dutch electronics company Philips.
} 
the rather unusual - at least as far as PhilTech is concerned-notion of 'the art of living.' In doing so, our cautious hope was to sidestep some of the, by now, equally institutionalized PhilTech discourse (such as on mediation, co-constitution, ...) and probe into its underlying assumptions.

In common English parlance, the term 'art of living' bears mainly the somewhat superficial flavor of 'lifestyle' concerns. Is the lighting in my house balanced? Does the furniture arrangement reflect my personality? The term's Latin counterpart, however, goes far back into philosophical history. In fact, ars vivendi in antiquity was almost synonymous with philosophy as such: it meant to provide people with practical, hands-on guidelines about how to live their lives. The Stoics, Epicureans, Cynics, Skeptics-all involved themselves intensely with the matter of how to live well, and this might mean among other things: ethically, elegantly, beautifully, joyfully, fully, wisely. Even before this period, the theme was important for Greek philosophers; the notion of 'care of the self' (technè tou biou) foreshadowed the later art of living theme and was called by for instance Michel Foucault an esthétique de l'existence (2001). The care of the self had a strong ethical connotation and concerned the dealing not only with oneself but also with others and the environment. Centuries later, after the medieval period, in which the 'art' element receded somewhat into the background, Michel de Montaigne was one of the first to pick it up again, followed later-in as many stilistic and methodological guises-by more recent thinkers such as Kierkegaard, Schopenhauer, Nietzsche, Heidegger, Sartre, and Foucault. Nowadays, the art of living as a philosophical notion is conceptualized mainly in Germany (by among others Gerd Achenbach and Wilhelm Schmid), the UK (by Alain de Botton), and The Netherlands (by Joep Dohmen), its proponents endeavoring to reinvigorate the rich traditions of Lebenskunst, often in a popularizing manner, with the purpose of handing their contemporaries tangible and workable advice.

Within these traditions, current or older, 'technology' is rarely thematized. ${ }^{2}$ One could for instance easily expect technology to be seen as a potential stumbling block on the road to living well. By contrast, it seems, in line with our foregoing considerations, technology gets to be implicitly accepted as an invisible, neutral backdrop to more plainly recognizable existential-psychological concerns. This is strange, to say the least, given that our contemporary world is, as also mentioned, filled to the brim with technologies. Perhaps they are too omnipresent to even deliberately reckon with? Maybe the 'art of living' approaches tend to take part in the common-sense instrumentalist perspective on technology? Or, otherwise, their representatives are for some or other reason not very interested in the subject... Within PhilTech, on the other hand, not 'the art of living' but instead the related notion of 'the good life' has a strong foothold (cf. e.g. Borgmann 1984; Higgs et al. 2000; Verbeek 2005; Brey et al. 2014). That concept does incorporate many of the issues at stake in the art of living traditions. At best, analyses along this line focus on what technology is, how it finds its place in society, how people relate to it. ${ }^{3}$ At worst, however, the notion of 'the good life' winds up being equated with a sort of clinical balancing act, in which technology figures as the balancing chord: it is simply 'there,' and one cannot do much more than develop the skills necessary for crossing. As such, living with technology becomes more of a technological practice, than an art.

\footnotetext{
${ }^{2}$ One notable exception can be found in the context of de Botton's School of Life project (cf. Chatfield 2012).

${ }^{3}$ One edited volume in Dutch refers explicitly to 'art of living': Technologie als levenskunst (Hogenhuis and Koelega 1996). It zooms in on issues such as responsibility, technology assessment, moral consultation, sustainability, participation, and democratization.
} 
In the colloquium, we sought to deliberately apply the idea of life conceptualized as an artistic, creative undertaking to the study of everyday interaction with technology. By putting forward the subtitle "Exploring the Range of Options from "Adoption" to "Rejection,", moreover, we wanted to provide a further heuristic guideline for experimentation, as to suggest that either of both-wholehearted adoption and wholehearted rejection-is still, or should still be, a possibility. Our intention was not to deal head-on with any of the aforementioned approaches or authors, rather we stimulated contributors to engage more with the spirit of the tradition. In the philosophy of technology, concepts potentially convergent with that spirit have been developed, by amongst others Feenberg, who with his theory of 'technical micropolitics' $(1995,1999)$ has outlined a comprehensive program of user appropriation or modification of technology. That very designation serves to illustrate that even in everyday projects of living and dealing with technology, 'the political' is never far off. Living with technology, indeed, never takes place in a vacuum. Thus, over and above personal choices ranging from 'adoption' to 'rejection,' there are of course larger overarching social, cultural, and political frameworks in which people partake and that may be said to vary on a scale from 'left,' e.g., (neo-)Marxist to 'right,' e.g., (neo)liberal. In the lectures we aimed to probe the interfaces between personal conduct and larger cultural contexts, in function of the question as to how a personal, existential 'art of living with technology' can be creatively conceived nowadays. By extension, in the articles collected here, the same concern is at stake.

\section{Consequences of the Empirical Turn}

It may constitute a less orthodox fashion of doing research, to proceed in this probing, 'feeling' way. We did and do not wish to directly critique, amend, or expand upon specific views, theorists, or models. Instead we sought and seek to approach things sideways, so to speak. But one may lay bare in this manner issues that are sometimes shrouded by conventional methods of theory-making. The latter are mostly based in either building upon or tearing down existing theoretical and disciplinary edifices. That's a fine way, however, of remaining largely stuck within one and the same vocabulary. By adding peculiar, unusual terms - 'the art of living with...'-it becomes possible to assess the very terms of a debate. And perhaps something new, something unexpected will eventually come out of the exercise.

Why the art of living with technology? We may turn the question around and ask, with just as much conceptual legitimacy: why not? The point is to examine the extent to which we can find workable, tangible ways of living with technology on the basis of insights and proposals developed within current PhilTech. Yes, contemporary PhilTech has in recent decades amply argued how we are on a fundamental level always 'co-' with technology. All the while, however, technologies, especially those of the nano-bio-info-cogno variety, have continued their relentless march into our lives. And it does feel like a veritable 'march into,' not a natural condition of 'co-habitation.' We still appear to want to patrol the last remaining borders between technology and-at least the idea of-(human) nature. This is exemplified in discussions on genetically modified organisms (GMOs), neural implants, certain reproductive technologies, robots, and so on. Though we may be not as vulnerable or witless in the face of technology as thought, it does often seem like an uneven battle: before we can even begin to evaluate the impact, technology has blurred yet another boundary between 'nature' and 'culture.' Can we keep up the assessing and the co-constructing, in times in which technology does, perhaps afresh, start to resemble Heidegger's Enframing? Put otherwise: PhilTech may have succeeded in offering various fruitful 
descriptions and definitions of technology, and even vistas for heightened awareness, empowerment, and change-but does that suffice? Should we also not ask whether the project of living with technology is in itself a technological matter, or not?

By prodding the authors and ourselves to reflect upon the idea of living 'artistically' with technology, we possibly already in advance and implicitly evoke the view that that project is indeed non-technological in character. Yet matters are not so simple. No strict distinction between technology and art can be traced, although that is at times suggested. If we go as far back as the Greeks, we find both still intertwined in the term technè. Throughout intellectual history, the idea of 'art' as a pure principle of creative genius got decoupled from the baser, dirty realities of material and logistical, thus 'technological,' practices. Nowadays we observe again, as is asserted sometimes, a mutual rapprochement between art and technology; in media art, digital arts, electronic arts, and the like. As if the two paths had ever been apart; while the fact of the matter is that art in its practice has never been technologyless. (Trivially speaking: brushes, pencils, easels, techniques such as perspective, ... all those are as much technological as Photoshop and iPads.) Hence, one could say, as inherently 'technological' humankind is, so naturally 'artistic' it is as well—or vice versa.

That is, however, not the 'problem.' What the contributions in this volume bring out, entails something else, something more profound and more pervasive. Very roughly put: we may need to embrace, as contemporary PhilTech indicates, technology as something 'of us,' as something by which we are 'co-constituted,' and that is 'co-shaped' by us; but does that make everything technological? According to post-'empirical turn' discourse, Heidegger, for one, was wrong in presenting technology as an all-devouring mode of being. We should not be 'afraid' of technology, because if one looks at it closely-i.e., empirically-one will always find ways of managing and steering it. However, judging from the material collected here, one can infer that the old humanistic concerns have everything but disappeared. We still are and should be worried, it turns out, about the protection of some 'human' safehouse against a potential 'technological' invasion of sorts. The safehouse is not an essence, as once suggested by classic PhilTech. It comprises more ephemeral things: very everyday ways of thinking, of socially interacting, of doing politics, of finding meaning in life, of dealing with uncertainties and setbacks. And the invasion is not by an all-encompassing force. It's more elusive, difficult to spot, and hard to map: the binary dynamics of digital technology, the canalizing mold of algorithms, the power (im)balances between owners and users, the economics of automization. And it is not just a matter of just using technology in the right way, the proper way: ethical, democratically accessible, conscious of side effects, ... There may be something about technology that we do not wish to affirm too passionately. Something that simply and intrinsically belongs to what it is. Was Heidegger-partially-right after all?

A crucial matter in this regard concerns the status of the so-called empirical methodology: as any philosopher or sociologist of science would be able to attest to, empirical research makes in itself for a frame that enables a particular view upon the world, of which the particularity, nevertheless, cannot be negated. The empirical method is a pair of glasses one dons, not the casting aside of all lenses and filters. True, under the 'empirical turn' banner, various takes on the concept of 'the empirical' can be found. And the kind of empiricism called for in PhilTech takes less from the tradition of natural science than from domains such as for instance phenomenology. Phenomenology - in its foundational Husserlian guise first of all-does not at all assume that a subject or observer could achieve something like a clear or neutral view on the observed. On the contrary, our perception is always shaped and determined by presuppositions and learned habits, and these in fact oftentimes harbor remnants of our modernist, for a large part Cartesian heritage. The 
phenomenological technique of bracketing or epoché is meant to put aside exactly these assumptions, the complex of which is known as the 'natural attitude.' Yet leaving behind the natural attitude and acquiring the 'phenomenological attitude' does not represent a silver bullet, an uncluttered way into truth. It requires effort, as it involves looking for and describing as many as possible aspects of a phenomenon. Still, the very idea of taking perception in the 'here and now' as its starting point, makes the phenomenological 'empirical' method a 'frame' - that 'frames' everything looked at through its prism—just as any other perspective.

Not all approaches within contemporary PhilTech share the phenomenological premise, however. Others are more inspired by methods hailing from anthropology, or history. The kind of empiricism profferred by Actor-Network Theory, for example, does not-completely-equal that of, say, postphenomenology. Such a disagreement about method and premises, by the way, constitutes one of the core issues at stake in the ongoing debate between postphenomenology and critical theory-inspired views. While the former criticize the latter for reverting too much to (neo-)Marxist dialectics of oppressor and oppressed, the latter accuse the former of neglecting political-social-economic factors and matters of power imbalances. All in all, what does this 'empirical' attitude in contemporary PhilTech actually mean? Perhaps it is, in general, not much more than an attitude at times. It certainly is sometimes more an element of discourse than an actual practice. Has the term 'empirical turn' acquired the character of a buzzword? As if we need to legitimate our existence as a purportedly 'serious' discipline by claiming: we are talking about real things, not crazy philosophical abstractions.

Admittedly, the 'empirical turn' banner has helped with the aforementioned institutionalization of the discipline. But perhaps exactly that institutionalization process has gone too far, and PhilTech has entered its very own cycle of 'normal science,' making it unable to perceive its own blind spots? One of the most poignant blind spots may be that it threatens to betray one of its initial aims: to find a middle road between the instrumentalism against which classic PhilTech was reacting, and the essentialism that classic PhilTech proposed as an alternative. Reacting all-too vehemently against the reaction, in its current shape, PhilTech may fall back eventually into instrumentalist ways of thinking. Or phrased differently: if we presume to all be 'co-,' technology and 'us,' we might come under the illusion that we can manage and steer all the way. That there isn't, and need not be, an 'outside technology.' And not only that: we might come under the belief that the art of living with technology knows no "no," as Heidegger's Gelassenheit did.

\section{Overview of the Special Issue}

This raises some questions. We do not and cannot offer clear-cut answers here. Moreover, the questions are what's most interesting, actually, for now. All the contributions in this volume wrestle in one way or another, either directly or indirectly, with them. The papers bring out these issues, mostly also without delivering distinct solutions-but as suggested, that was not the goal. Exactly by reflecting upon the notion of the art of living with technology, many of the contributors got into some 'exploratory mode,' discovering that 'artistically' living with technology is the exploration, in itself and as such: letting something grow, cautiously, experimentally, stepwise, provisionally, modestly, in a trial and error dialectic.

On an editorial-technical level, in the spirit of this 'probing' and of sparking a conversation rather than solving problems, we adopted the 'open peer commentary' approach. 
This entails that two peers are invited to write a commentary on a 'core' paper, that is then published together with the paper. After that, the author of the initial core paper writes a 'final reply' to the commentators. We have nine core papers and two reviewers for each. Together with the reply, that leads to a sort of kaleidoscopic conceptual universe of 36 'voices.' It is impossible to give all these voices their right due here, in a limited amount of space; the papers will have to speak for themselves for the most part, but we do endeavor to give a brief overview of the themes treated of, especially in function of the overarching theme.

Starting where classic PhilTech left off, Marc Van den Bossche's article points out the lasting pertinence of the Heideggerian notion of Gelassenheit (releasement). The key is to see it against the background of Heidegger's so-called nihilistic moment: releasement confronts us with the groundlessness of being, but from there on, we may go further and obtain a new relation to technology. Bob Scharff in his commentary contests Van den Bossche's interpretation and his claim that this Heideggerian perspective can complement Feenberg's and Ihde's insights. Van den Bossche in his reply clarifies that he seeks to situate Heidegger's notions inside a new vocabulary, one that goes beyond detailed exegesis of original texts but is fitted for our times. Babette Babich expands more poetically upon the theme, connecting Gelassenheit to the Japanese concept of wabi sabi.

Asian philosophy is also an inspiration for Michel Puech, who wants to base the art of living with technology in the Eastern-philosophical notion of non-confrontation. Nonconfrontation radically differs from Western methods of and views on living well, that are often grounded in conflictual dynamics of a sort. Commentators Tsjalling Swierstra and Erik Paredis deem the approach interesting and promising, but remark that Puech leaves out a couple of important considerations. What problems does non-confrontation exactly set out to solve? And stressing that idea so much, does one not lose sight of broader social and political constellations? A withdrawal into individual, non-confrontational modes of coping may consolidate and obscure those constellations. In his reply, Puech grants the criticism and actually argues that the choice of the 'personal' perspective is a conscious one.

Pieter Lemmens, whose article represents the most 'critical' one of the collection, would not agree with sticking to individual approaches either. We need to collectively struggle first and foremost, to fight cognitive and consumerist capitalism's destruction of social autonomy. Bernard Stiegler and post-operaism offer useful frameworks from which to give shape to that fight. Kate Milberry in commenting, however, is not convinced that the Stieglerian concept of pharmakon will even do: we have to change the social relations of capitalism as such; that can only be achieved through an ethic of care and of love. Peter-Paul Verbeek, then, finds Lemmens' neo-Marxist 'struggle' dialectic defective and his argument lacking in empirical evidence. Lemmens in his reply comes back with a restatement of the Stieglerian viewpoint, demonstrating that it is not dialectical in nature-in the process critically assessing the empirical turn, and in fact calling for a 'transcendental (re)turn.'

Other authors also search for fresh approaches. Some do this by evaluating the statute of ethics within PhilTech. Steven Dorrestijn, for one, develops a critique of Verbeek's theory of mediated morality. According to Dorrestijn, mediation theory conflates the notions of mediation and ethics, as it regards the former as ways of dealing with the latter. But provocatively stating that "while it is true that technical mediation is all around, technical mediation is not all there is," he proposes that mediation-our condition of being hybrid beings-should actually be perceived as the problem ethics is meant to tackle. And this asks for a slightly different interpretation of Foucault's later work about the care of the self than Verbeek offers. Commentators Marli Huijer and Galit Wellner supplement the argument by pointing out that we also require a critical analysis of the subjectivities that 
technologies help to affirm, and by a more specific analysis tailored to the 'posthumanist' situation and on the basis of insights from Self Determination Theory, respectively.

Mark Coeckelbergh, too, evaluates ethics of technology, advising it to re-strengthen its ties with aesthetics. More precisely, ethics and aesthetics alike should be about coping with human existential vulnerability, for information and communication technologiesCoeckelbergh's main focus here-transform our 'vulnerabilities.' David Gunkel adds that hacking may be a fruitful notion, able to guide us in this work. Hub Zwart places vulnerability coping in the context of Hegel's master and slave dialectic, and by way of a reading of the movie and novel Limitless challenges Coeckelbergh's claim that 'modern heroism' implies the overcoming of vulnerability by way of technology. Coeckelbergh, in turn, responds by bringing novels and films by Houellebecq, DeLillo, and Cronenberg into the debate, demonstrating that these works are perhaps not to be called completely modern, and in any case, the modern endeavor to 'overcome,' says Coeckelbergh, is deluded.

That the art of living with technology naturally flows over into matters of education, is shown by the contributions of Andrew Feenberg and Søren Riis. Feenberg subjects educational technology to a new critical investigation, observing that it serves to strengthen neo-liberal perspectives on university reform, often cast in terms of purported 'progress.' But it is a rhetorical strategy that cloaks the negative effects these reforms have on education and academic values. Ellen Rose reads Feenberg's contribution as still too much grounded in the idea that we can correct the ills by making different design decisions. Feenberg clarifies in his reply that he shares the skepticism, but does not think the situation is hopeless. Evan Selinger supplements Feenberg's argument with a reflection on big data and the ways in which universities attempt to capitalize on it.

Riis, then, along similar lines as Feenberg, satirizes the rhetorics of 'progress' coupled to the introduction of technology in classrooms, though he talks more about education in general. He calls for 'ICT literacy,' worked out on the basis of a (post)phenomenological analysis of how technologies work in educational practice and mediate the teacher-pupil relationship. Robert Rosenberger further elaborates and refines this proposal by developing the notion of the 'ICT educator's fallacy,' in analogy to Ihde's 'designer fallacy': educational technology will not necessarily have exactly the effects that the educator (i.e., designer) expects from it. Joris Vlieghe, also drawing on Stiegler and in a somewhat more critical vein, would rather defend a 'technical' form of digital literacy than a 'non-technical' one, as he perceives Riis to do. Riis in replying corrects to the extent that he finds both essential.

This curious mix of technical and non-technical is also at stake in Ike Kamphof's contribution. Kamphof illustrates, by way of a case study on tele-monitoring technology and the way in which this impacts upon how homecare workers deal with clients' privacy, that the art of living with technology does not exclusively have to take the form of deliberation: it can also emerge as a more modest process of 'reflection-in-action.' Also here, a critique of Verbeek's mediation theory is implied: the 'aesthetic reflexivity' has less to do with the shaping of subjectivities than with the creation and maintenance of good relationships. The commentators agree with Kamphof's general argument, but supplement it on several points. Jeannette Pols suggests to also take into account the affective character of people's 'technological relationships.' Tamar Sharon highlights what makes Kamphof's approach special and specific: the focus on micro-events instead of macro-events and on the relation with others instead of the relation with the self.

Finally, also building on the notion of 'reflexivity,' Yoni Van Den Eede seeks to work out an 'epistemology of technology use,' founded on of the distinction between concrete and abstract. The art of living with technology can from this perspective be characterized as a probing and skillful practice of navigating ladders of abstraction. Commentator Ian 
Angus stresses that it is important to not revert to either concreteness or abstraction; and a critical theory of digital media must, given these media's characteristics, circle around the 'cultural unconscious.' Corey Anton reflects further upon some of the ambiguities within the concepts of the concrete-abstract dichotomy and that of users and communities. Van Den Eede, in replying, elucidates his rhetorical stance, making clear that his purpose is in the first instance emancipatory: finding ways to think beyond the immediately given concrete, to uncover the 'abstract conditions' giving shape to that 'concrete.'

\section{Closing Remarks: Technology Versus Reflexivity}

We must once again, and finally, repeat: most of this reflecting is done, quite deliberately, in a rather exploratory spirit. Yet the contributions at hand can also be seen to lay bare several pertinent issues - though elusive and subtle they may be. Often these issues center on specific dichotomies: individual versus collective, technical versus non-technical, economic versus 'social,' good versus bad, hope versus despair, ... The most important and pressing one among that list, for the discipline of PhilTech, may be the distinction between 'technological' and... something else. In agreement with some of the papers, we could call that something else 'reflexivity.' There may be something 'outside of' technology. A way of critical-deliberative-reflexive thinking, of looking, of feeling, of experiencing, of keeping one's distance; much like Heidegger suggested. Something that is not reducible to technology, or vice versa. That tension, between technology and reflexivity (or whatever one may choose to term it), ushers us into a process of disciplinary soulsearching.

After the empirical turn, we learned to resign ourselves to the idea that technology is here to stay and it's not going anywhere. In post- 'empirical turn' terms, then, living with technology becomes a technological affair. That means, a tautology: living is always already with technology. But to the extent that we have not and perhaps cannot ever wholly come to terms with it, living with technology is also clearly non-technological. Yes, technology may be 'us,' but it still works in specific ways. It has characteristics, affordances, that push one into a certain direction, instead of another. A social media newsfeed models our worldview in specific ways, an e-health app changes the patient-caretaker relationship, a completely digitalized or informationalized bureaucratic apparatus will make for certain societal constellations instead of others. And, as mentioned, this may be due to factors that go beyond mere modes of usage. The question then becomes: can post'empirical turn' PhilTech sufficiently cope with these issues? Phrased otherwise, it stresses the 'co-' aspects, but doesn't it with that emphasis lose sight of other, 'non-co-' aspects?

As said, in thinking this issue through, we appear to find that the status of the empirical turn as such becomes at stake. This in a double-sided way. On one hand, we need to inquire whether we have become not 'overly' empirical. On the other hand, nevertheless, we may with just as much reason, and at the same time, ask if we are already 'sufficiently' empirical. For one, among the contributions, Ike Kamphof's meticulously executed case study illustrates this well. Indeed, it seems that the empirical attitude, when consequently elaborated in practice — as Kamphof does—rather than just being paid lip service, does allow saying something non-technological about 'living with technology.' Perhaps, the empirical turn has not yet gone far enough?

All this, in closing, is not to say that we should suddenly start to radically revise hardwon insights. The idea that living with technology is technological, should definitely count as an improvement upon previous essentialist views-however tautological it may be. 
According to classical logic, a tautology does not convey anything meaningful. And in a sense, much post- 'empirical turn' parlance can be seen as confirming the obvious: we are technological beings. In a Wittgensteinian vein, nonetheless, tautologies can be situated on the borderline between the set of meaningful propositions and nonsense, in between sense and nonsense. That is to say, they are senseless. A tautology in this view delineates the space of possible meaningful propositions; it is a necessary perspective that is laid onto the world and which enables relevant knowledge to emerge. In other words, our flank movement along the lines of the art of living, insofar as it addresses the question whether living with technology is technological or not, probes into the very premises of the postempirical turn discourse of PhilTech.

\section{References}

Achterhuis, H. (2001). American philosophy of technology: The empirical turn (trans: Robert P. Crease). Bloomington: Indiana University Press.

Borgmann, A. (1984). Technology and the character of contemporary life: A philosophical inquiry. Chicago: University of Chicago Press.

Brey, P., Briggle, A., \& Spence, E. (Eds.). (2014). The good life in a technological age. London: Routledge.

Chatfield, T. (2012). How to thrive in the digital age (the school of life). London: Macmillan.

Feenberg, A. (1995). Alternative modernity: The technical turn in philosophy and social theory. Berkeley: University of California Press.

Feenberg, A. (1999). Questioning technology. London: Routledge.

Foucault, M. (2001). Une esthétique de l'existence (entretien avec A. Fontana). In Dits et écrits II. 19761988 (pp. 1549-1554). Paris: Gallimard.

Heidegger, M. (1977). The question concerning technology. In The question concerning technology and other essays, translated by William Lovitt (pp. 3-35). New York: Harper Perennial.

Higgs, E., Light, A., \& Strong, D. (Eds.). (2000). Technology and the good life?. Chicago: The University of Chicago Press.

Hogenhuis, C., \& Koelega, D. (Eds.). (1996). Technologie als levenskunst. Visies op instrumenten voor inclusieve technologie-ontwikkeling. Kampen: Uitgeverij Kok.

Verbeek, P.-P. (2005). What things do: Philosophical reflections on technology, agency, and design, translated by Robert P. Crease. University Park, PA: The Pennsylvania State University Press.

Verbeek, P.-P. (2009). Let's make things better: A reply to my readers. Human Studies, 32(2), 251-261.

Yoni Van Den Eede is a postdoctoral fellow of the Research Foundation-Flanders (FWO), affiliated with the research groups Centre for Ethics and Humanism (ETHU) and Culture, Emancipation, Media \& Society (CEMESO), both at the Free University of Brussels (VUB). He conducts research into the philosophy of technology, media theory and media ecology, with an emphasis on phenomenological, cultural, existential and political themes, and is the author of Amor Technologiae: Marshall McLuhan as Philosopher of Technology (Brussels, VUBPRESS, 2012) and of Mens en media. Van Marshall McLuhan tot een hedendaagse filosofie van media en technologie (Tielt, LannooCampus, 2014).

Gert Goeminne is a postdoc researcher at the Centre for Sustainable Development (Ghent University). Holding a PhD in physics (2001), he currently investigates the politics of sustainability from a Science and Technology Studies perspective. His main research interests pertain to the hybrid socio-technical character of sustainability controversies such as climate change and genetically modified food, thereby investigating how understandings and representations of these issues are inherently linked to the ways in which we choose to address them.

Marc Van den Bossche is Professor of Philosophy at the Free University of Brussels (VUB). He teaches philosophical anthropology and philosophy of culture, and studies from these perspectives the role of technology in contemporary society. Other research interests include the theme of embodiment, hermeneutics, religion, interculturality, aesthetics, art, and most recently photography and digital arts. He 
acts as a member of the Board of Directors of the Society of Phenomenology and Media and is on the board of the Charles Sanders Peirce Society and that of the Nederlands Wijsgerig Genootschap voor Pragmatisme (Dutch Philosophical Society for Pragmatism). He also is part of the Global Advisory Board of the Human Dignity and Humiliation Studies. His publications include Kritiek van de technische rede. Een onderzoek naar de invloed van techniek op ons denken (Utrecht, 1995), Natuur en lijfelijkheid. Proeven van een esthetisch denken (Utrecht, 1998), Ironie en solidariteit. Een kennismaking met het denken van Richard Rorty (Rotterdam, 2001), Het pathos van het denken. Opstellen over subjectiviteit en intersubjectiviteit (Budel, 2003, 1st edition, Brussels, 2012, 2nd edition), Ironie et solidarité. Une introduction au pragmatisme de Richard Rorty (Paris, 2004), Wielrennen (Rotterdam, 2005), Sport als levenskunst (Rotterdam, 2010), Religie na de dood van God (Brussel, 2013), Le sport, un art de vivre (Bruxelles 2013), Leven na de dood. Dagboek van een rouwproces (Rotterdam, 2014). 